\title{
Papers
}

\section{Strategic asset allocation - Liability benchmarking and dynamic risk budgeting}

Received (in revised form). 1st December, 2004

\begin{abstract}
Alan Brown
is Group Chief Investment Officer and Vice Chairman of State Street Global Advisors worldwide. He holds an MA in Physics from Cambridge University and serves on the Advisory Council for the CFA Centre for Financial Market integrity. He is also on the board of the Centre for Economic Research and Graduate Education-Economic Institute (CERGE-El), attached to the Charles University in Prague.
\end{abstract}

\begin{abstract}
The debate on reforming pension fund best practice has raged now for over three years, with more attention devoted to defined benefit (DB) than defined contribution (DC) plans. The pension fund industry has carefully managed the relatively small risk between the portfolio and its benchmark while ignoring the much larger risk between the benchmark and the plan's liabilities. This paper proposes a more general optimal portfolio solution which explicitly takes into account a fund's shifting wealth (or funding ratio) and risk premia. This new approach leads to a path-dependent process directly linked to a fund's liabilities and suggests ways in which best practice should be modified. It also considers the implications for DC plans as the same essential arguments apply to all long-term savings pools regardless of their precise nature. It concludes that a DC, age-based default solution can accommodate the needs of many participants with different wealth levels.
\end{abstract}

Keywords: asset allocation; liability benchmarking; risk budgeting; dynamic risk allocation; strategic policies; separating alpha and beta

\section{Pension shortfalls, regulatory pressure shift focus to liabilities}

The average funding ratio for US pensions declined from 116 per cent at the end of 1999 to just 75 per cent at the end of 2002. ${ }^{1}$ Similar shortfalls plague plans throughout the rest of the world. For as long as equity markets were providing double-digit returns, it was not surprising that many plan sponsors were focused more heavily on asset returns than plan liabilities. Yet even good returns on assets do not necessarily guarantee solvency for a pension plan. As we have seen, declining interest rates can lead to a greater increase in the present value of liabilities than the present value of the assets, due to the liabilities' much longer duration. Indeed, a three-year bear equity market, which reduced asset levels, and a 40-year low in interest rates, which increased the present value of liabilities, have forced a shift in concern toward pension plan liabilities as the ultimate performance benchmark. 
In addition, regulatory pressure is responding to heightened investor interest in companies' pension plan liabilities and funding status and their effects on shareholder value. The UK's new financial reporting standard FRS 17 requires companies to account for pension assets and liabilities on their balance sheets as of 2005 . Under the rule, pension plan assets must be measured using market values; plan liabilities must be valued using a projected unit method and discounted at an AA corporate bond rate; and the pension plan surplus or deficit must be recognized in full on a company's balance sheet. $^{2}$

\section{Previous best practice ignored gap between assets and liabilities}

The large swings in funding from surplus to deficit showed that assets and liabilities were not always well matched under previous best practice. That was due in large part to the conventional benchmarking approach which started from the perspective of assets, whether defined by an index, a specific portfolio or a chosen group of portfolios. This static benchmark did not vary with time and became the starting point for measuring risk and a key driver of returns. On closer examination, it was clear that the tracking error between actual investments and the strategic benchmark was far lower than the tracking error between assets and liabilities, which ultimately determined the plan's success or failure.

The strategic asset class benchmark was derived from asset/liability modelling. That exercise was followed by an implementation plan which typically assigned a combination of core and satellite managers whose performance was monitored to ensure they were tracking or outperforming their individual mandates. The process was repeated every three to five years. Doing the asset allocation study every three years and running the fund relative to this static benchmark, however, could produce huge fluctuations in the funding ratio.

This was perhaps the most serious shortcoming of conventional practice. In the microeconomic theory of saving and consumption, solutions to multi-period problems that remain static through time are known as 'myopic' and can work only if the investor is indifferent to changing levels of wealth and risk, which is rarely the case with pension funds. ${ }^{3}$ The previous method also treated liabilities as of they were static rather than changing as the discount rate moves up or down. Using a single-period optimisation process supplemented with stress testing, the previous method could be best described as a 'guess and test' approach which focused on terminal expected values while ignoring interim changes in plan funding and risk premia. It assumed constant expected risks and returns, and the Monte Carlo simulations used overlooked important mean reversions to fair value as well as correlations across asset classes.

\section{Strategic policies not benchmarks}

Establishing a static strategic benchmark assumes a constant risk appetite regardless of a plan's wealth level or changing rewards for taking risk over time. It is the financial equivalent of setting sall to Bermuda with all canvas up the mast and not changing course or trimming the sails regardless of the weather encountered on the way. The largest share of governance effort is devoted to managing risks to the strategic benchmark, which are almost always small, while ignoring the much greater 
risks between that benchmark and the plan's expected liabilities. Such gross oversimplifications may have been necessary in the past for the lack of a better method, but there is a sounder approach today.

In the real world, risk appetite does change with wealth, not necessarnly in a simple way or in the same way for all investors, but in almost all cases it will change. It may be that the implied covenant between the sponsoring organisation and the trustees is so strong that the trustees risk appetite doesn't change. But in the vast majority of cases, especially for funds in deficit - sadly a commonplace problem these days - the sponsoring organisation is not indifferent to the level of contributions it must make. If there is any question about the willingness or ability of the sponsor to provide additional contributions, trustees may well feel they must take risk off the table as surplus positions erode, in effect locking in a more certain result by limiting or eliminating the possibility of a further decline.

Finance theory has established models for making sensible estimates of ex-ante risk premia. It is reasonable to expect that when risk premia are high, investors should be more willing to take on risk, all other things being equal; the opposite would hold when risk premia are low. These two factors should vary inversely: if equity prices fall relative to bonds, surpluses typically decline; whereas the equity-bond risk premia would typically rise.

Modelling this, however, requires calculating complicated path dependencies regarding uncertain liabilities as well as carrying out optimisation processes over many different time intervals. The theory of how to allocate assets to meet changing liabilities has been clear since Robert Merton's work on optimal portfolio construction more than 30 years ago, but only very simple problems could be addressed until recently. ${ }^{+}$Three academics, building on Merton's work recently produced a more general optimal portfolio solution in an intertemporal context. ${ }^{5}$

Encouragingly, today's mean-variance solution is a part of the more general solution. There are two additional terms, however, which hedge against changes in the risk-free rate and risk premia. The degree of hedging depends on the investor's wealth and risk aversion. Today's mean-variance solution would be optimal only if either expected risk premia were constant or an investor's risk appetite was genuinely invariant to changes in wealth.

Understanding the limitations of previous best practice leads to the conclusion that instead of trying to establish a strategic benchmark, investors need to form a strategic policy, a kind of investment roadmap, which states in advance what to do as wealth and risk premia shift, according to a fund's specific risk preferences. This is the centrepiece of liability benchmarking, in which assumptions about the changing nature of asset allocation and liabilities are made explicit and transparent. This new approach to asset allocation requires several important shifts in thinking.

First, clients need to articulate their risk preferences at different levels of surplus (wealth) and at different levels of expected reward (risk premia). This will require close review with consultants and fund managers but will result in a strategic policy that is far more attuned to an individual plan's needs. These preferences are then translated into so-called utility functions.

While utility functions are complicated to derive, the concept behind them is straightforward. They essentially map how the risk appetite of a fund will 
change as surpluses rise and fall and risk premia go up or down. For example, a sponsor is most likely less happy and less willing to take risk when a plan is 80 per cent funded than when it is 100 per cent funded. Alternatively, a plan could reach an overfunded status and decide to reduce risk in order to preserve its surplus. Getting a board to focus on how a fund should respond to different combinations of funding ratio and risk premia illuminates the true risk appetite of the fund. This in turn provides a more meaningful basis for strategic asset allocation decisions.

Monitoring managers assigned this type of mandate becomes a slightly more complex task, since meeting or exceeding a benchmark is no longer the sole performance criterion. Instead, the first step is to determine if the manager complied with the client's risk preferences given the plan's actual wealth level and expected returns. The manager must not only establish an appropriate risk budget, he must 'spend' that risk wisely.

Under the new approach, the risk budget is changing in two dimensions: with wealth and with expected returns. More importantly, this dynamic framework makes the correlations between assets and liabilities more transparent. For example, the real liabilities of a pension fund are driven in part by the level of real wage growth. But real wage growth depends on real corporate earnings growth, which in turn determines stock market returns. While it is difficult to incorporate these kinds of linkages with any kind of precision, it is better to attempt an estimate than to ignore them entirely.

While this new paradigm is perhaps more complex than conventional practise, we believe trustees and sponsors will come to acknowledge its advantages. Allowing asset allocation to change as wealth and expected returns move seems so very sensible, and could have saved the industry a great deal of trouble over the last three years. Today's asset/liability modelling framework is clearly based on unrealistic assumptions. Changing old habits is never easy, but leaders amongst funds, consultants and fund managers will move in this new direction, albeit slowly and carefully.

Ultimately the industry will no longer unquestioningly take on beta risk to the market. The starting point for a fund will be its liabilities and its risk appetite, or risk budget. That risk budget will be employed for both alpha and beta strategies. Most importantly, alpha and beta will increasingly be managed separately, which will have important implications for portfolio construction, manager selection, management fees and added returns.

\section{Reforming unrealistic accounting practices}

There is, however, a paradoxical accounting rule that needs to be resolved before the new approach can be successfully implemented. In the US pension world, a variation on the trick question, 'Is a pound of lead or a pound of feathers heavier?' is 'which is worth more: US $\$ 1 \mathrm{~m}$ of equities or US $\$ 1 \mathrm{~m}$ of bonds?' Under US accounting rules, US $\$ 1 \mathrm{~m}$ of equities is clearly worth more because plans are allowed to assume a higher rate of return even before it is earned. Of course the reason US $\$ 1 \mathrm{~m}$ of a higher returning asset like equities is actually worth the same as US $\$ 1 \mathrm{~m}$ dollars of lower returning bonds is because equities are riskier. These actuarially based valuation techniques smooth results but divert attention from the real level of risk assumed.

A similar situation has prevailed in the UK where it is common to discount the 
liabilities of a pension plan at a rate determined by an actuary according to the asset mix. If a fund has a high equity content, it can assume a higher rate of return and therefore a higher discount rate. Almost magically, liabilities decrease. This kind of practice meant that mature funds in a deficit position may not even have had the practical option of raising their bond content because the impact on the liability side would have been just too great. In reality, however, the liabilities don't change because the asset mix has changed. FRS17 will take care of this in the UK, but not in the US.

\section{Implementing a dynamic risk allocation model}

Having sketched the idea of a new dynamic risk allocation model, let us look at how it would change current practice. The first step would be to go back to basics and examine the strength of the covenant between the sponsoring organisation and the fund. On the basis of this, and with an understanding of the risk tolerance of the sponsor, the trustees and the beneficiaries they represent, a manager and consultant would determine a utility function which expresses how the risk appetite of the fund will change as its surplus rises or falls, and as risk premia go up and down. There are straightforward ways of doing this. For example, trustees could ordain that under no circumstances should the plan's solvency fall below a certain measurement. Or trustees could agree to a specific confidence level that all known liabilities can be met at current contribution rates. It would then be up to the manager and the consultant to agree a utility function that is likely to lead to the desired result. This new process effectively defines a strategic policy to replace the strategic benchmark of today. After that, the process is remarkably similar that of today.

\section{Stage two}

Like today, an implementation plan is required. Under new practice, however, the risk budget will not be static but rather fluctuate as the plan's fortunes unfold over time. A risk budget will be established for beta strategies aimed at securing market returns as well as one for alpha strategies devoted to finding skill and gaining excess returns.

The main task for the alpha side of the strategy is to choose managers who can add value. The only difference is that it no longer matters which asset class they manage. The client can allocate assets to managers and markets wherever active management opportunities are believed to be most favourable, separating the alpha and beta decisions. The beta risk budget is allocated to one manager who sits over all the others. This overlay manager's prime responsibility is to manage the risk budget in line with the fund's shifting wealth and shifting risk premia. $\mathrm{He}$ is not, however, making judgements based on short-term views of market returns as with a tactical asset allocation overlay manager. The beta managers will implement their strategy through a combination of physical investments and derivatives.

\section{Funding and monitoring managers}

The most important difference in funding and monitoring managers is the changed role of the beta manager. This is the manager whose interests should now be totally in line with the trustees' overall objectives as expressed by the strategic policy defined in the first stage. Monitoring this manager will have two aspects: whether the manager operated with an appropriate ex-ante risk level given the surplus position of the fund and expected risk-premia; and 
whether he used the risk budget effectively.

\section{Liability benchmarking in a DC context}

While it may seem that these kinds of solutions are relevant only for sophisticated DB plans, the same general approach can be applied to defined contribution plans. One of the few advantages that DC plans have over DB ones is that they have no specific regulatory solvency limits. In a DB world, all sorts of different regimes exist depending on which country you look at. The regulatory regime will probably have a very significant impact on the utility function funds that are likely to be chosen and may well make them much more sensitive to short-term changes in funding ratios than would be the case for a typical DC investor. Indeed, for a DB fund, a reasonable question is whose utility function should be chosen: that of the plan sponsors, the trustees or some aggregate of the beneficiaries?

In a DC fund it is at least clear that the utility function in question is that of the beneficiary. While there may be quite a wide range of sensitivities to risk within a DC fund, some sensible general statements about risk would probably apply to most.

- many participants would value a floor to their wealth;

- wealth for a DC participant is no different in a real sense to that of a $\mathrm{DB}$ fund. It is the ratio of assets/liabilities needed to provide the retirement income of choice;

— as a result, changes in liabilities influence wealth just as much as changes in assets.

Researchers at State Street Global Advisors recently analyzed a realistic scenario to determine how sensitive asset allocation might be to different levels of funding ratios and different terms to retirement. (The capital market and asset liability assumptions are shown in the appendices.) The utility function chosen maximised the retirement funded level while minimising the volatility of the funding level.

This review showed that in the absence of specific and relatively short-term solvency limits, asset allocation is much more sensitive to changes in the number of years to retirement than the funding ratio. So, for example, the greatest sensitivity to funding ratio changes came five years before retirement. Changing the funding ratio by 20 per cent shifted the allocation to risky assets (non-bond assets) by 5 per cent. Whereas moving from 30 years before retirement to 5 years changed the exposure to risky assets by about 30 per cent (see appendices). In other words, participants with the same number of years to retirement should have similar asset allocations, regardless of the implicit funded status. Of course, any individual with inadequate funding will need to contribute more to reach his target. Whatever assets he has, however, should be allocated in a similar way to someone with the same number of years unt1l retirement. This supports the notion that a well thought-out, age-based default solution can meet the needs of many beneficiaries, even if their individual funding ratios are dissimilar.

\section{Future of asset management}

Institutional investors faced with funding shortfalls and modest market returns will increasingly recognise that the industry's current idea of best practice is seriously flawed. Slowly but inevitably the world of strategic benchmarks will yield to strategic policies that start with the 
liabilities. That shift will move the industry much closer to absolute rather than relative returns and the separation of alpha and beta in DB plans will be much more widely accepted. As new market opportunities develop, the increasing challenge for investment managers will be to balance alpha and beta risk budgets within a dynamic asset allocation framework.

A practical solution is not such a large step away from today's practice, once the notion of strategic policies that manage assets and liabilities in a dynamic framework supplant the current model of static benchmarks. While much of current practice will remain essentially unchanged, the beta manager's main task will for the first time be directly aligned with the trustees' goals; fulfilling those will determine his rewards. Unlike today's practice, a fund's surplus position will be directly managed so that trustees will no longer have to sit helplessly by as their plan's surpluses rise and fall beyond their control.

Finally, even in a DC context it is possible to design a default solution which is likely to meet the real needs of most participants, provided of course they are willing to recognise how much they need to contribute to stand a chance.

\section{References}

1 Watson Wyatt tabulations of Compustat US Disclosure database, compiled from SEC filings

2 Accounting Standards Bodrd (UK), (2(x)(0) November.

3 Foley, T (2003) 'Establishing a Strategy Polıcy', State Street Global Advisors, 8 October

+ Merton, R. (1969) 'Lifetime Portfolio Selection Under Uncertanty The Continuous Time Case', Renew of Economics and Stattstics, Vol. 51, pp $2+7-257$

5 Detemple, J, Garcia, $R$ and Rindisbacher, $M$ (2)(13) A Monte Carlo Method for Optmal Portfolios', Journal of Finance, February

\section{Appendices}

Table 1: Capital market assumptions

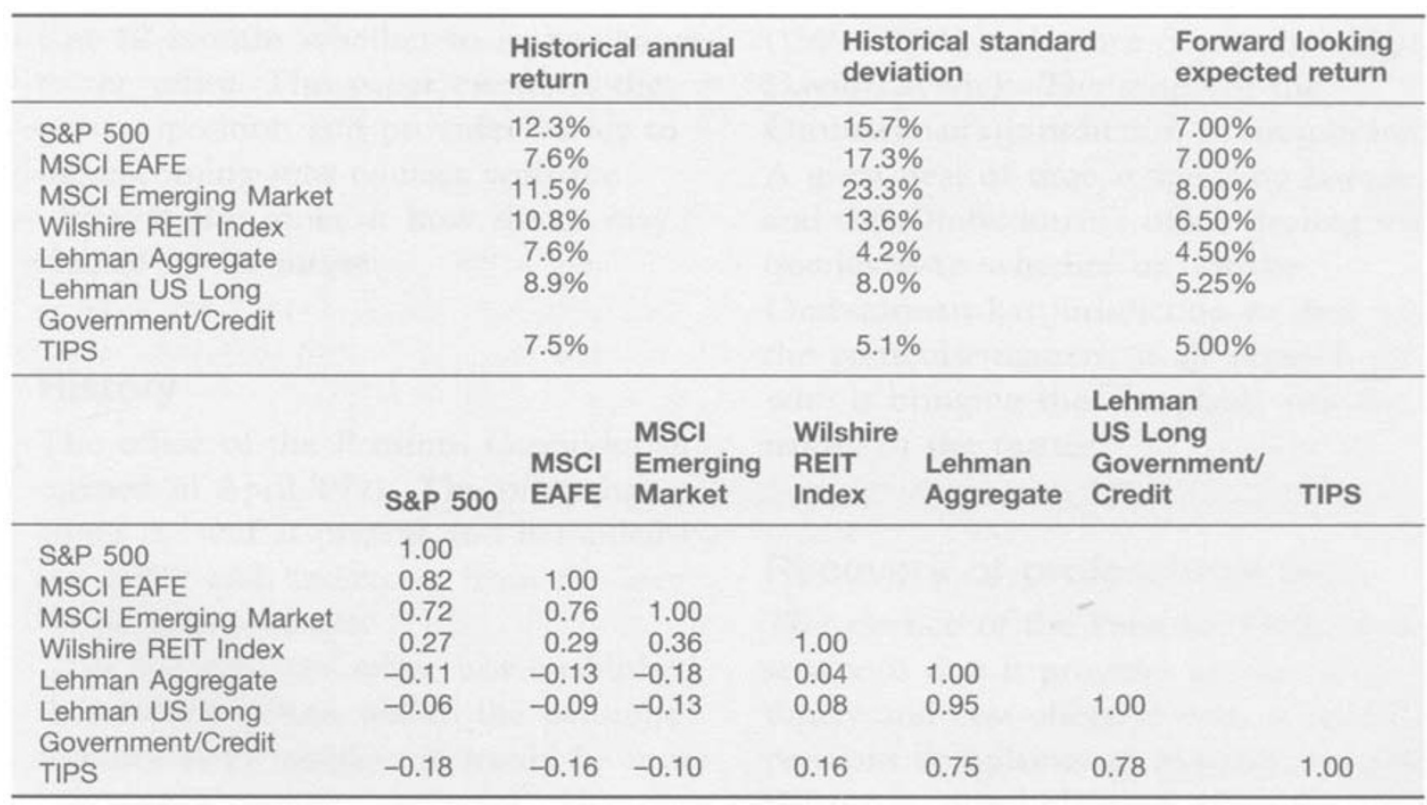




\section{Brown}

Table 2: Asset liability assumptions

Annual Contribution 12 per cent of salary

Annual Salary scale: inflation plus 1.5 per cent

Expected retirement benefit 70 per cent of ending salary each year

Average years after retirement 20 years

Objective: Maximise retirement funded level subject to minimising the volatility of the funded level

Table 3: Age-based allocation

\begin{tabular}{|c|c|c|c|c|c|c|c|c|}
\hline & \multicolumn{2}{|l|}{$T-30$} & \multicolumn{2}{|l|}{$T-20$} & \multicolumn{2}{|l|}{$T-10$} & \multicolumn{2}{|l|}{$T-5$} \\
\hline & $\begin{array}{l}\text { initial } \\
10 \%\end{array}$ & $\begin{array}{l}\text { initial } \\
30 \%\end{array}$ & $\begin{array}{l}\text { initial } \\
40 \%\end{array}$ & $\begin{array}{l}\text { initial } \\
60 \%\end{array}$ & $\begin{array}{l}\text { initial } \\
70 \%\end{array}$ & $\begin{array}{l}\text { initial } \\
90 \%\end{array}$ & $\begin{array}{l}\text { initial } \\
90 \%\end{array}$ & $\begin{array}{l}\text { initial } \\
110 \%\end{array}$ \\
\hline S\&P 500 & $32.0 \%$ & $30.0 \%$ & $28.5 \%$ & $27.0 \%$ & $25.0 \%$ & $24.0 \%$ & $20.0 \%$ & $19.0 \%$ \\
\hline MSCI EAFE & $23.0 \%$ & $22.0 \%$ & $19.5 \%$ & $18.7 \%$ & $18.5 \%$ & $17.0 \%$ & $15.0 \%$ & $13.5 \%$ \\
\hline MSCI Emerging & $5.0 \%$ & $6.0 \%$ & $3.5 \%$ & $2.3 \%$ & $2.5 \%$ & $2.0 \%$ & $2.0 \%$ & $0.0 \%$ \\
\hline Wilshire REITS & $10.0 \%$ & $9.0 \%$ & $5.0 \%$ & $5.0 \%$ & $4.0 \%$ & $4.0 \%$ & $4.0 \%$ & $3.5 \%$ \\
\hline Lehman Aggregate & $9.3 \%$ & $10.0 \%$ & $13.0 \%$ & $14.3 \%$ & $17.2 \%$ & $19.0 \%$ & $20.5 \%$ & $21.0 \%$ \\
\hline Lehman Long & $14.8 \%$ & $16.0 \%$ & $21.9 \%$ & $23.7 \%$ & $24.0 \%$ & $24.5 \%$ & $30.5 \%$ & $33.0 \%$ \\
\hline TIPS & $6.0 \%$ & $7.0 \%$ & $8.6 \%$ & $9.0 \%$ & $8.8 \%$ & $9.5 \%$ & $8.0 \%$ & $10.0 \%$ \\
\hline Portfolio Return & $6.4 \%$ & $6.4 \%$ & $6.1 \%$ & $6.1 \%$ & $6.0 \%$ & $5.9 \%$ & $5.8 \%$ & $5.7 \%$ \\
\hline Risk & $10.5 \%$ & $10.2 \%$ & $8.8 \%$ & $8.2 \%$ & $7.8 \%$ & $7.3 \%$ & $6.4 \%$ & $5.5 \%$ \\
\hline
\end{tabular}

